\title{
Relationship between C-Reactive Protein and Cardiovascular Diseases in Patient with ESRD
}

\author{
Mamun MAA ${ }^{1}$, Hasan MM², Khan FA ${ }^{3}$, Hossain M$^{4}$, Morshed SM ${ }^{5}$, Gupta RD
}

Conflict of Interest: None

Received: 17.02 .2020

Accepted: 27.07 .2020

www.banglajol.info/index.php/JSSMC

Key Words:

ESRD, C-reactive protein,

Cardiovascular diseases.

\begin{abstract}
Background-Cardiovascular mortality is significantly higher in ESRD patient. There are various risk factors for development of cardiovascular diseases including traditional risk factors, factors unique to ESRD patients and emerging risk factors.It is believed that their combined actions are integrated in the progression of atherosclerosis and inflammation plays a central role. C-reactive protein is a valuable marker of inflammation. Determination of serum creactive protein levels may be a useful predictor of cardiovascular diseases in ESRD patients

Objective-To find out relationship between c-reactive protein and cardiovascular diseases.

Methods- This cross sectional study was carried out into department of Nephrology, Dhaka Medical College Hospital, Bangladesh following fulfillment of inclusion and exclusion criteria. For analytical purpose total study population were divided into two groups on the basis of creactive protein level. Patients having c-reactive protein $\leq 6 \mathrm{mg} / \mathrm{L}$ were considered as group $A$ and $>6 \mathrm{mg} / \mathrm{L}$ were considered as Group B. The differences between groups were analyzed by unpaired t-test, fisher' exact test or chi-square $\left(X^{2}\right)$ test. Multivariable regression analysis was done to see the association between c-reactive protein and cardiovascular diseases.
\end{abstract}

Results- Patients with raise c-reactive protein have significantly higher cardiovascular disease than that of normal c-reactive protein. Multivariable linear regression analysis after adjusting for age, sex, smoking and diabetes shows that subject with CRP $\leq 6 \mathrm{mg} / \mathrm{L} v \mathrm{~s}>6 \mathrm{mg} / \mathrm{L}$ had 1.51 (95\% CI 1.02 to 2.19) times increase risk of having cardiovascular disease.

Conclusion- Inflammatory process has a role in development of cardiovascular diseases in ESRD patient.

[J Shaheed Suhrawardy Med Coll 2020; 12(2): 95-99] DOI: https://doi.org/10.3329/jssmc.v12i2.56890

\section{Introduction}

The mortality of patients with end stage renal disease (ESRD) remains high, with most deaths resulting from cardiovascular disease $^{1}$. Several authors ${ }^{2,3}$ have found that overall mortality and cardiovascular mortality were

1. Dr. Md. Abdullah Al Mamun, Assistant Professor, Department of Nephrology, Shaheed Suhrawardy Medical College, Dhaka.

2. Dr. Mohammad Mirazul Hasan, Indoor Medical Officer, Department of Nephrology, Shaheed Suhrawardy Medical College Hospital, Dhaka.

3. Dr. Fazla Alahi Khan, Assistant Professor, Department of Nephrology, Abdul Malek Ukil Medical College, Noakhali.

4. Dr. Momtaz Hossain, Assistant Professor, Department of Nephrology, Mugda Medical College, Dhaka.

5. Dr. Syed Mahbub Morshed, Department of Nephrology, Shaheed Suhrawardy Medical College, Dhaka.

6. Dr. Ratan Das Gupta, Associate Professor and Head, Department of Nephrology, Shaheed Suhrawardy Medical College, Dhaka.

Correspondence to: Dr. Md. Abdullah Al Mamun, Assistant Professor, Department of Nephrology, Shaheed Suhrawardy Medical College, Dhaka. Mobile : 01770440619, E-mail: mamunabdullah@yahoo.com significantly higher in hemodialysis patients with elevated c-reactive protein. There are several risk factors for development of cardiovascular diseases in ESRD patients. These are traditional risk factors including age, sex, hypertension, diabetes, smoking, hypercholesterolaemia. Factors unique to ESRD patients are anemia, elevated calcium-phosphorus product. And emerging risk factors include inflammation, hyperhomocystenaemia and accumulation of endogenous inhibitiors of nitric oxide synthase. It is believed that their combined actions are integrated in the progression of atherosclerosis ${ }^{4}$ and inflammation plays a central role. C-reactive protein is a valuable marker of inflammation. There are many clinical and experimental studies have shown that c-reactive protein may contribute directly to the pathogenesis of atherosclerosis and its complications ${ }^{5}$. Increase c-reactive protein is a strong risk factor for death within one year in patient with chronic kidney disease ${ }^{6}$. Furthermore, 
elevated c-reactive protein levels have been identified as a risk factor for cardiovascular disease in healthy men ${ }^{7}$. Statistical modeling, calculation of relative risk and cost considerations indicate that determination of serum creactive protein levels may be a useful predictor of cardiovascular diseases in ESRD patients ${ }^{4}$.

\section{Methods}

This cross sectional study was carried out into the Department of Nephrology, Dhaka Medical College Hospital, Dhaka in the period December 2012 to November 2013 following fulfillment of inclusion and exclusion criteria. An informed written consent from patient was taken. Every patient had gone through detailed history taking- particulars of the patients and medical history includes patient had acute and chronic infection, malignancy, on any anti-inflammatory drugs, renal transplant recipient, had coronary artery diseases or other cardiovascular diseases. Meticulous physical examination was done.

Newly diagnosed ESRD patients were examined after admission into hospital and before undergo dialysis whereas on maintenance hemodialysis patients were examined just after dialysis. Laboratory investigations like hemoglobin concentration, serum creatinine, c-reactive protein, ECG, ECHO were done.

Statistical analyses were performed by using SPSS 16.0 (Statistical Package for Social Science, Inc., Chicago, IL, USA). Continuous variables were expressed as means \pm standard deviation and categorical variables as frequencies and proportions. For analytical purpose total study population were divided into two groups on the basis of c-reactive protein level. Patients having c-reactive protein $\leq 6 \mathrm{mg} / \mathrm{L}$ were considered as group A and $>6 \mathrm{mg} / \mathrm{L}$ were considered as Group B.

The differences between groups were analyzed by unpaired t-test, fisher' exact test or chi-square $\left(\mathrm{X}^{2}\right)$ test. Multivariable regression analysis was done to see the association between c-reactive protein and cardiovascular diseases.

\section{Results}

The study included 98 ESRD patients. Study population was divided into two groups. Group A comprises those who had c-reactive protein $<6 \mathrm{mg} / \mathrm{L}$ and Group B comprises those had c-reactive protein $>6 \mathrm{mg} / \mathrm{L}$. Group A belonged 23 patients and group $B$ belonged 75 patients. Majority of the patients (39.1\%) were age belonged to 31-40 years in group A and in group B majority (30.7\%) belong to 51-60 years. About three fourth (73.9\%) patients were male in group A and 68\% in group B. Out of 98 patients $64.29 \%$ patients were unemployed and $61.2 \%$ patients reside in rural area. Smoker were found to be $21.7 \%$ in group A and $42.7 \%$ in group B. Glomerulonephritis was the leading cause of ESRD followed by diabetes mellitus with or without hypertension and others.

Hypertensive were found to be $78.3 \%$ in group A and $98.7 \%$ in group B, diabetic were $8.7 \%$ in group A and $33.3 \%$ in group B whereas cardiovascular disease was present $13 \%$ patient in group A and $100 \%$ patient in group B. Differences between two groups were statistically significant $(\mathrm{p}=0.002,0.020,0.001$ respectively). Regarding type of cardiovascular diseases, most of the patient had left ventricular hypertrophy and it was found to be $13 \%$ in group A and $37.3 \%$ in group B followed by ischemic heart disease, left ventricular failure and others. Multivariable linear regression analysis after adjusting for age, sex, smoking and diabetes shows that subject with CRP d" $6 \mathrm{mg} / \mathrm{L}$ vs $>6 \mathrm{mg} / \mathrm{L}$ had 1.51 (95\% CI 1.02 to 2.19 ) times increase risk of having cardiovascular disease.

Table I

Age distribution of the study patients and relation with CRP ( $n=98)$.

\begin{tabular}{lccccc} 
Age & Group $A(n=23)$ & Group $B(n=75) P$ & \\
(in year) & $n$ & $\%$ & $n$ & $\%$ & value \\
\hline$\leq 20$ & 0 & 0.0 & 1 & 1.3 & \\
$21-30$ & 6 & 26.1 & 12 & 16.0 & \\
$31-40$ & 9 & 39.1 & 11 & 14.65 & \\
$41-50$ & 5 & 21.7 & 20 & 26.7 & \\
$51-60$ & 1 & 4.3 & 23 & 30.7 & \\
$>60$ & 2 & 8.7 & 8 & 10.65 & \\
Mean \pm SD & $38.61 \pm 11.5$ & $46.55 \pm 13.1$ & $0.010^{\mathrm{s}}$ \\
Range (min-max) & $24-65.0$ & \multicolumn{1}{c}{$19-75.0$} & \\
\hline
\end{tabular}

$\mathrm{s}=$ significant

$\mathrm{P}$ value reached from unpaired t-test

Table I shows that majority (39.1\%) patients were age belonged to 31-40 years in group A and 23(30.7\%) in group $\mathrm{B}$ belong to 51-60 years. The mean age was found $38.61 \pm 11.5$ years in group A and 46.55 \pm 13.1 years in group B. The mean age difference was statistically significant $(\mathrm{p}<0.05)$ between two groups. 


\section{Table II}

Distribution of the study patients by smoking status and relation with $C R P(n=98)$.

Smoker Group A(n=23) Group B(n=75) P

\begin{tabular}{lccccc} 
& $\mathrm{n}$ & $\%$ & $\mathrm{n}$ & $\%$ & value \\
\hline Yes & 5 & 21.7 & 32 & 42.7 & $0.070^{\text {ns }}$ \\
None & 18 & 78.3 & 43 & 57.3 & \\
\hline
\end{tabular}

$\mathrm{ns}=$ not significant

$\mathrm{P}$ value reached from chi square test

Table II shows that 5(21.7\%) were smoker in group A and $32(42.7 \%)$ in group B. The difference was not statistically significant $(\mathrm{p}>0.05)$ between two groups.

\section{Table III}

Distribution of the study patients by etiology of ESRD and relation with $C R P(n=98)$.

Etiology of Group A(n=23) Group B(n=75) P

\begin{tabular}{lccccc} 
ESRD & $\mathrm{n}$ & $\%$ & $\mathrm{n}$ & $\%$ & value \\
\hline GN & 18 & 78.3 & 32 & 42.7 & $0.002^{\mathrm{s}}$ \\
HTN & 2 & 8.7 & 16 & 21.3 & $0.142^{\text {ns }}$ \\
DM & 1 & 4.3 & 6 & 8.0 & $0.478^{\text {ns }}$ \\
DM \& HTN & 1 & 4.3 & 18 & 24.0 & $0.028^{\mathrm{s}}$ \\
ADPKD & 1 & 4.3 & 3 & 4.0 & $0.663^{\text {ns }}$ \\
\hline
\end{tabular}

$\mathrm{s}=$ significant, $\mathrm{ns}=$ not significant

$P$ value reached from chi square test.

Table III shows that GN were found $18(78.3 \%)$ in group A and $32(42.7 \%)$ in group B. HTN were found $2(8.7 \%)$ in group A and $16(21.3 \%)$ in group B. DM were found $1(4.3 \%)$ in group A and $6(8.0 \%)$ in group B. DM \& HTN were found $1(4.3 \%)$ in group A and $18(24.0 \%)$ in group B. ADPKD were found $1(4.3 \%)$ in group $A$ and $3(4.0 \%)$ in group B. The GN difference was statistically significant $(p<0.05)$ between two groups.

\section{Table IV}

Distribution of the study patients by blood pressure status and relation with CRP $(n=98)$.

\begin{tabular}{lccccc} 
HTN & Group A(n=23) & Group $B(n=75)$ & $P$ \\
& $n$ & $\%$ & $n$ & $\%$ & value \\
\hline Present & 18 & 78.3 & 74 & 98.7 & $0.002^{\mathrm{s}}$ \\
Absent & 5 & 21.7 & 1 & 1.3 & \\
\hline
\end{tabular}

$\mathrm{s}=$ significant

$\mathrm{P}$ value reached from fisher exact test
Table IV shows that HTN was present $18(78.3 \%)$ in group A and $74(98.7 \%)$ in group B. The difference was statistically significant $(\mathrm{p}<0.05)$ between two groups.

Table V

Distribution of the study patients by diabetes mellitus and relation with $C R P(n=98)$.

Diabetes MellitusGroup A(n=23)Group B(n=75) P value

$\begin{array}{cccccc} & \mathrm{n} & \% & \mathrm{n} & \% & \\ \text { Present } & 2 & 8.7 & 25 & 33.3 & 0.020^{\mathrm{s}} \\ \text { Absent } & 21 & 91.3 & 50 & 66.7 & \end{array}$

$\mathrm{s}=$ significant

$P$ value reached from fisher exact test

Table V shows that diabetes mellitus was present 2(8.7\%) in group A and $25(33.3 \%)$ in group B. The difference was statistically significant $(\mathrm{p}<0.05)$ between two groups.

\section{Table VI}

Status of cardiovascular diseases among study patients and relation with $C R P(n=98)$.

CVD Group A(n=23)Group B(n=75) P value

$\begin{array}{cccccc} & \mathrm{n} & \% & \mathrm{n} & \% & \\ \text { Present } & 3 & 13.0 & 75 & 100.0 & 0.001^{\mathrm{s}} \\ \text { Absent } & 20 & 87.0 & 0 & 0.0 & \end{array}$

$\mathrm{s}=$ significant

$\mathrm{P}$ value reached from fisher exact test

Table VI shows that CVD was present $3(13.0 \%)$ patients in group A and $75(100.0 \%)$ in group B. The difference was statistically significant $(\mathrm{p}<0.05)$ between two groups.

\section{Table VII}

Distribution of the study patients according to type of cardiovascular diseases and relation with CRP $(n=98)$.

Cardiovascular Group A(n=23) Group B(n=75) P

\begin{tabular}{lccccr} 
disease & $\mathrm{n}$ & $\%$ & $\mathrm{n}$ & $\%$ & value \\
\hline Absent & 20 & 87.0 & 0 & 0.0 & \\
Present & & & & & \\
Ischemia & 0 & 0.0 & 13 & 17.34 & \\
Ischemia with LVH & 0 & 0.0 & 6 & 8.0 & \\
LVH & 3 & 13.0 & 28 & 37.3 & \\
Old MI & 0 & 0.0 & 11 & 14.7 & $0.001^{\mathrm{s}}$ \\
Old MI with LVH & 0 & 0.0 & 12 & 16.0 & \\
Old MI with LVF & 0 & 0.0 & 4 & 5.33 & \\
Ischemia with & 0 & 0.0 & 1 & 1.33 & \\
Arrhythmia & & & & & \\
\hline S= significant & & & & \\
P value reached from chi square test &
\end{tabular}


Table VII shows that $3(13.0 \%)$ patients had LVH in group A and 28(37.3\%) in group B. Others result are depicted in the table. The difference was statistically significant $(p<0.05)$ between two groups.

\section{Table VIII}

Multivariable regression analysis for association between CVD and CRP levels ( $n=98)$.

OR 95\% Confidence Interval P (Lower, Upper) value

\begin{tabular}{lccc}
\hline Age (years) & 0.24 & $(1.01,1.37)$ & $0.074^{\text {ns }}$ \\
$\begin{array}{l}\text { Sex (male vs } \\
\text { female) }\end{array}$ & 0.06 & $(0.12,0.93)$ & $0.464^{\text {ns }}$ \\
CRP $(\leq 6 \mathrm{mg} / \mathrm{L}$ & 1.51 & $(1.02,2.19)$ & $0.001^{\mathrm{s}}$ \\
vs $>6 \mathrm{mg} / \mathrm{L})$ & & & \\
Smoker & 1.32 & $(0.32,2.87)$ & $0.048^{\mathrm{s}}$ \\
Diabetes & 1.45 & $(0.22,3.03)$ & $0.087^{\mathrm{ns}}$ \\
\hline
\end{tabular}

$\mathrm{S}=$ significant, $\mathrm{ns}=$ not significant.

TableVIII shows that a subject with CRP $\leq 6 \mathrm{mg} / \mathrm{L}$ vs $>6$ $\mathrm{mg} / \mathrm{L}$ had 1.51 (95\% CI 1.02 to 2.19 ) times increase in odds having cardiovascular disease. A subject with smoker had 1.32 (95\% CI 0.32 to 2.87 ) times increase in odds having cardiovascular disease. Age, sex and diabetes were not significantly associated with cardiovascular disease.

\section{Discussion}

This cross sectional study was carried out with an aim to find out relationship between c- reactive protein and cardiovascular diseases in patients with ESRD. Total 98 diagnosed case of ESRD (both maintenance hemodialysis and pre dialysis) were included in this study as per inclusion criteria. The study patients were divided into 2 groups based on CRP level. Normal CRP $(\leq 6 \mathrm{mg} / \mathrm{L})$ and high CRP $(>6 \mathrm{mg} / \mathrm{L})$ were considered as group A and group $\mathrm{B}$ respectively.

In this study mean age was found $38.61 \pm 11.5$ years in group A and $46.55 \pm 13.1$ years in group B. The mean age was significantly $(\mathrm{p}<0.05)$ higher in group B. Similarly, Menon et al. (2003) found that mean age was $50 \pm 12.6$ (SD) years and $56.1 \pm 10.4$ years in group A group and group B respectively, which was significantly $(\mathrm{p}<0.05)$ higher in group B. The reason of elevated c-reactive protein associated with older age is not clear. But it may be due to ESRD patient with older age has various co-morbidity resulting in raise c-reactive protein. In this current study it was observed that $21.7 \%$ were smoker in group A and $42.7 \%$ in group B. The difference was not statistically significant ( $p>0.05$ ) between two groups. Menon et al.
(2003) showed current smoker were found $9.0 \%$ in group A and $11.0 \%$ in group B. Elsaid, (2009) showed smoker were $16.5 \%$ of their study patients, which are lesser with the current study. ${ }^{8}$

Regarding the etiology it was observed that glomerulonephritis (GN) were found $78.3 \%$ in group A and $42.7 \%$ in group B. Hypertension (HTN) were found $8.7 \%$ in group A and $21.3 \%$ in group B. Diabetes (DM) were found $4.3 \%$ in group A and $8.0 \%$ in group B. Diabetes \& Hypertension were found $4.3 \%$ in group $A$ and $24.0 \%$ in group B. Elsaid, (2009) obtained that the cause of chronic renal failure in $41.0 \%$ patients were due to diabetic nephropathy, in $20.0 \%$ patients due to hypertension, $6.0 \%$ patients chronic glomerulonephritis, $4.0 \%$ hypoplastic kidney, $3.0 \%$ lupus nephritis, $22.0 \%$ were unknown etiology, other causes included were obstructive uropathy $2.0 \%$, tubulo-interstitial nephritis $1.0 \%$ and contrast nephropathy in $1.0 \%$. This dissimilarity was due to glomerulonephritis still the major cause of CKD in our country.

In this study it was observed that HTN was present $78.3 \%$ in group A and $98.7 \%$ in group B. HTN was significantly $(p<0.05)$ higher in group B. Elsaid (2009) and Alharbi and Enrione (2012) showed $81.0 \%$ and $54.5 \%$ respectively of their study patients were hypertensive, ${ }^{9}$ which are comparable with the current study. It was observed that diabetes was present $8.7 \%$ in group $A$ and $33.3 \%$ in group B. Diabetes was significantly $(\mathrm{p}<0.05)$ higher in group $B$. Similarly, Menon et al. (2003) showed that diabetes was $3.0 \%$ and $11.0 \%$ in group $A$ and group $B$ respectively, that indicates that diabetes was higher in group $\mathrm{B}$, which is comparable with the current study. Elsaid, (2009) also showed diabetes mellitus were $44.0 \%$ in their study patients. In this present study $39.1 \%$ patient was on dialysis in group A and $57.3 \%$ in group B, which is higher in group B but not statistically significant ( $p>0.05$ ).

In this present study it was observed that cardiovascular diseases (CVD) was present $13.0 \%$ patients in group A and all patients in group B. That indicate patient having cardiovascular diseases have significantly higher creactive protein than that of patients without cardiovascular diseases. Atherosclerotic processes play a major role to develop cardiovascular diseases. Inflammation is closely associated with atherosclerosis and c-reactive protein is an important marker of inflammation. Similarly, Menon et al. (2003) showed history of CVD was found $11.0 \%$ in group A and $19.0 \%$ in group B. Manjunath et al. (2003) showed cardiovascular disease in $5.8 \%$ of their study patients. In another study Shlipak et al. (2003) found renal insufficiency present in $11.0 \%$ patients of their cardiovascular health study participants. ${ }^{10}$ 
As regards the type of cardiovascular diseases it was observed in this current study that $13.0 \%$ patients had LVH in group A and $37.3 \%$ in group B. Whereas ischemia found $17.34 \%$, ischemia with LVH $8.0 \%$, LVH $37.3 \%$, Old MI 14.7\%, Old MI with LVH 16.0\%, Old MI with LVF $5.33 \%$ and Ischemia with Arrhythmia (Supraventricular tachycardia) $1.33 \%$ in group B. Foley et al. (1995) studied on ESRD patient where $74 \%$ patients had LVH and $19 \%$ had ischemia ${ }^{11}$. Both of the study results are comparable.

In multivariable linear regression analysis, after adjusting for age, sex, smoking, diabetes a subject with CRP d"6 mg/ $\mathrm{L}$ vs $>6 \mathrm{mg} / \mathrm{L}$ had 1.51 (95\% CI 1.02 to 2.19 ) times increase in odds having cardiovascular disease. A subject with smoker had 1.32 (95\% CI 0.32 to 2.87 ) times increase in odds having cardiovascular disease. Age, sex and diabetes were not significantly associated with cardiovascular disease.

Similarly, Menon et al. (2003) obtained that median CRP level was higher $(P<0.001)$ in subjects with a history of CVD (CRP, $0.46 \mathrm{mg} / \mathrm{dl}$ ) compared with those without CVD (CRP, $0.22 \mathrm{mg} / \mathrm{dl}$ ). In multivariable logistic regression analysis, the odds of CVD were 1.73 times greater in patients with high CRP levels $(>0.6 \mathrm{mg} / \mathrm{dl})$ than those with low CRP levels (e"0.6 mg/dl).

Here it could be said that c-reactive protein is an independent risk factors like others for development of cardiovascular diseases in ESRD patient. Diabetes, age and sex were not signified in this study probably due to small sample size.

\section{Conclusion}

From this study it has been shown that high c-reactive protein $(>6 \mathrm{mg} / \mathrm{L})$ is associated with 1.5 times increase risk for cardiovascular diseases in ESRD patient. So it could be concluded that inflammatory processes have a role in the development of cardiovascular diseases in ESRD patient.

\section{References}

1. Abraham G, Moorthy AV, Aggarwal V. 2006. Chronic Kidney Disease: a silent epidemic in Indian subcontinent-strategies for management. J Ind Med Assoc,104 (12):689-91.

2. Muntner, P., He, J., Hamm, L., Loria, C., Whelton, P.K., 2002. Renal insufficiency and subsequent death resulting from cardiovascular disease in the United States. J Am Soc Nephrol. 13(3): pp.745-53.

3. Manjunath, G., Tighiouart, H., Coresh, J., Macleod, B., Salem, D.N., Griffith, J.L., et al. 2003. Level of kidney function as a risk factor for cardiovascular outcomes in the elderly. Kidney International, 63, pp.1121-1129

4. Zoccali C, Mallamaci F, Tripepi G.2004. Inflammatory proteins as predictors of cardiovascular disease in patients with end-stage renal disease. Nephrol Dial Transplant, 19(5):pp67-72.

5. Arici, M. and Walls, J. 2001. End-stage renal disease, atherosclerosis and cardiovascular mortality: is c-reactive protein the missing link? Kidney International, 59:407-414.

6. Bergstrom et al. 1995.Elevated serum CRP is a strong predictor of increased mortality and low serum albumin in hemodialysis patient. J Am Soc Nephrol, 6, pp.573.

7. Menon, V., Wang, X., Greene, T., Beck, G.J., Kusek, J.W., Marcovina, S.M., et al. 2003. Relationship between CReactive Protein, Albumin, and Cardiovascular Disease in Patients With Chronic Kidney Disease. American Journal of Kidney Diseases, 42, 1, pp 44-52.

8. Elsaid, S.A. 2009. Nutritional assessment of patients in a large dialysis Saudi center. JNRT, 2(2): pp. 17-27.

9. Alharbi, k., Endrione E.B., 2012. Malnutrition is prevalent among hemodialysis patients in Jeddah, Saudi Arabia. Saudi J Kidney Dis Transpl. 23(3): pp. 598-608.

10. Shilpak, M.G., Fried, L.F., Crump, C., Bleyer, A.J., Manolio, T.A., Tracy, R.P.,et al, 2003. Elevations of inflammatory and Procoagulant Biomarkers in Elderly Persons with Renal insufficiency. Circulation, 107: pp. 87-92.

11. Foley RN, Parfrey PS, Harnett JD,Kent GM, Martin CJ, Murray DC et al. 1995. Clinical and echocardiographic disease in patients starting end stage renal disease therapy. Kidney Int 47: pp. 186-192. 